\title{
Elaboration and Evaluation of Contents about Hearing Health Inserted in Cybertutor
}

\author{
Camila de Castro Corrêa ${ }^{1}$ Ricelly Avila da Silva ${ }^{1}$ Wanderléia Quinhoneiro Blasca ${ }^{1}$ \\ ${ }^{1}$ Department of Speech-Language Pathology and Audiology, Bauru \\ School of Dentistry, Universidade de São Paulo, Bauru, São Paulo, \\ Brazil \\ Address for correspondence Camila de Castro Corrêa, BS, Bauru \\ School of Dentistry, Universidade de São Paulo, Al. Octávio Pinheiro \\ Brisola, 9-75-17012-901 Bauru, São Paulo, Brazil \\ (e-mail: camila.ccorrea@hotmail.com).
}

Int Arch Otorhinolaryngol 2014;18:115-121.

\begin{abstract}
Introduction Cybertutor (electronic tutor) is a type of information and communication technology to disseminate knowledge about hearing, aiming at the prevention of hearing alterations and, when needed, early treatment, in addition to social inclusion of the hearing impaired. However, it is important to evaluate the level of language used in the content and the subjective perception of the target public regarding improvements of the tool.

Objective To improve content about hearing health inserted in a cybertutor and to evaluate the level of legibility and the quality of the content and material made available.

Method For the construction of the content, text and audiovisual resources were

Keywords

- hearing

- speech

- language and hearing sciences

- education

- distance

- primary prevention

- health education

- information technologies and communication projects used, based on scientific publications, and were evaluated objectively with Flesch Reading Ease test and subjectively with a questionnaire created by the authors and answered by 10 ninth-year pupils.

Results Two modules on hearing health were created, "Hearing Health" and "Intervention and Rehabilitation," which received Flesch scores of 50.8 and 51.4\%, respectively, making it necessary to have a sixth- to ninth-year education to understand the material. The students' evaluation in reference to language and material showed that 55.5\% considered the contents excellent; $38.2 \%$ classified the contents as satisfactory; $6.3 \%$ considered them reasonable; and $0 \%$ classified them as unsatisfactory.

Conclusion The contents inserted in the cybertutor about hearing health presented a language level considered easy for the age group of the target population, in addition to receiving good subjective evaluation from the pupils, facilitating access to the information.
\end{abstract}

\section{Introduction}

Based on the data supplied by the Instituto Brasileiro de Geografia e Estatística (Brazilian Institute of Geography and Statistics), ${ }^{1}$ there are at least 5.7 million people in Brazil with incapacitating hearing deficiency, and most of them depend on services provided by the Unified Health System (SUS). The SUS offers free hearing health services from prevention to treatment and management, including hearing devices and cochlear implants from accredited services of low, average, and high complexity in audiology, located in different regions of the country. ${ }^{2}$

However, even with the provision of free services, it was verified by the Service of Audiology of São Paulo that among 162 individuals with hearing losses, only $25 \%$ of the patients received the diagnosis by the first year of life and only $11 \%$ received

May 3, 2013

accepted

August 4, 2013
DOI http://dx.doi.org/

10.1055/s-0033-1358578. ISSN 1809-9777.
Copyright $(2014$ by Thieme Publicações License terms Ltda, Rio de Janeiro, Brazil 
had initiated speech therapy intervention soon after the diagnosis. ${ }^{3}$ One attempt to justify the delayed and inadequate treatment for hearing losses is avoidance of labeling individuals as "hearing-impaired."4

However, important actions have been taken to change this, such as the Newborn Hearing Screening, which provides early diagnosis as well as identification of individuals at risk for hearing loss, making longterm followup possible. ${ }^{5}$

Education on issues of health has proposed the creation of a productive chain of knowledge, where information is transmitted in a continuous way, leading to behavioral changes to promote health. Telehealth, specifically the modality of interactive telehealth, facilitates the dissemination of knowledge in auditory health for the development of professionals who work in this field as well as for the population to learn about hearing aiming at health promotion and the important aspects of social inclusion of the hearing impaired.

Therefore, for the promotion of health by means of the interactive teleducation, several modern resources, both didactic and dynamic, exist, making it possible for knowledge to reach a larger number of people of different socioeconomic levels and age groups and involving the population in their role inside the community. ${ }^{6}$

Information and communication technologies (ICTs) in the work with hearing health are valuable tools, making more dynamic action and better interaction, access, and motivation to the user possible. One example is the cybertutor (electronic tutor), which allows interactive follow-up through the Internet of the student's progress as well as provides discussion on the theme with the use of forums. It is distinguished for being dynamic, saving instructor's time, and its motivational character, in addition to supplying the information in different formats: texts, figures, videos, animations, and links to others Web sites. ${ }^{7}$ Thus, users' autonomy in searching knowledge and their responsibility to access the proposed contents surfaces, organizing themselves within their available schedules (study flexibility).

The electronic tutor can be used for the transmission of diversified knowledge, adjusting it to a target population, because its language is adapted (made compatible with the age group and level of study of the population), in addition to considering if the proposed subject is of interest and importance for such a population.

For the evaluation of language level, there are indexes such as the Flesch Reading Ease Test that evaluate the length of the words (considering the number of syllables) and the length of the phrases (calculating the number of words), resulting in a percentage that characterizes the document in a legibility level. ${ }^{8}$ The bigger the percentage, the easier the reading of the text (closer to $100 \%$ ), and the closer to $0 \%$, the more difficult the text, demanding a higher level of instruction (schooling).

However, only counting words and syllables does not allow for a precise idea of how the target population evaluates the material because content at a satisfactory level of legibility can still present errors in context. It is necessary to use questionnaires that measure aspects of the language by means of subjective evaluation and aspects of illustrative/graphic information and understanding of the material as a whole.
With this in mind, a study was conducted to train 13 students in the second year of an undergraduate course in speech and language pathology on contents of personal sound amplification devices in addition to verifying the satisfaction in this process. For this, the students had access to cybertutor; they then evaluated their satisfaction with the tool in the learning of the content proposed. ${ }^{9}$

Subsequently, the content, the language, and the aesthetic aspect when adjusted for the target population converge to motivate and interest the user to access the material, guaranteeing the involvement of the user in the proposal in question. The objective was to create contents in a cybertutor regarding hearing health and to objectively evaluate the level of legibility and to subjectively evaluate the quality.

\section{Methods}

This descriptive prospective study quantitatively and qualitatively evaluated educational material inserted in an ICT tool. The study received process no. 164/2010 from the Committee of Ethics in Research of the Faculdade de Odontologia de Bauru and was developed in conjunction with the Department of Speech and Language Pathology of the FOB-Universidade de São Paulo.

For the construction of the contents in the electronic tutor (cybertutor), indexed books and scientific articles were searched, selecting, summarizing, and adapting the language of the material in addition to choosing audiovisual resources to make the educational material motivating and attractive; parts of the videos of the CD-ROM "Homem Virtual da Audição," ${ }^{10}$ CD-ROM "Homem Virtual-Aparelho de Amplificação Sonora Individual,"11 DVD "A comunicação com o aparelho auditivo,"12 and DVD "Conhecendo e aprendendo sobre o meu aparelho auditivo" 13 were included.

From the final material, legibility level was assessed using the Flesch Ease of Reading Index (FERI; score from 0 to 100 , the higher the score, the bigger the degree of easiness of reading of the text). ${ }^{8}$ For this, the Microsoft Office "show legibility statistics" Word tool was selected, thus at the end of the orthographic review, the corresponding percentage to the FERI appeared.

Ten students of both genders, aged 13 to 15 years old, voluntarily participated in completing a questionnaire created by the authors. All 35 students from a ninth year of a public school of Bauru, São Paulo were invited to participate in the research. Those who showed interest and whose parents signed the Clarified and Informed Consent form were included.

The access to the content via cybertutor was available to the participants for 2 weeks, housed in the page of the Young Doctor Project (http://www.projetojovemdoutor.org.br; -Fig. 1), and created by the team of the Course of Telemedicine of the Universidade de São Paulo.

The authors used as a basis the principles of attribution and updates of the modified Heath on Net Code to elaborate the questions, in addition to the characteristics for the evaluation of the quality of the material, quality/placement of the illustrations, and ease of understanding (-Table 1 ). The inspiration of the modified Heath on Net Code is justified by 


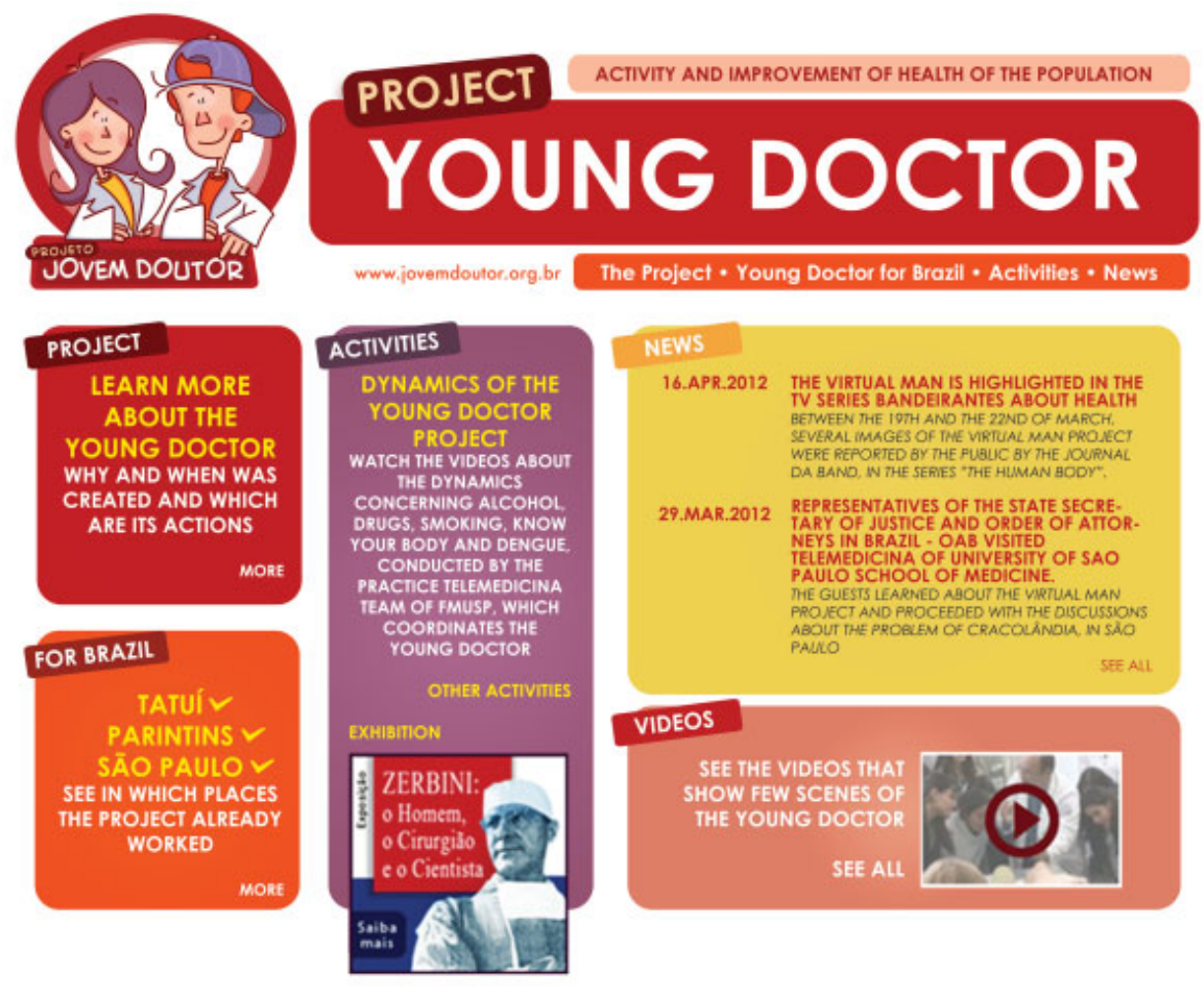

Fig. 1 The website of the "Young Doctor Project" is in Portuguese (www.jovemdoutor.org.br).

the objective of the seven principles in assuring the quality of the information about health available in the Internet. ${ }^{14}$

However, the questionnaire contained other criteria to emphasize the opinion of the target population when accessing cybertutor about the material and the language, and there was the concern to simplify the questions and the options for answers (excellent, satisfactory, reasonable, and unsatisfactory) to avoid confusion. Moreover, the researchers emphasized that there was no grading; only the students' opinion was needed so that the tool could be perfected.
The results were organized by means of descriptive statistical analysis of the FERI and the questionnaire about the individuals' opinion about cybertutor, relating both the evaluated aspects.

\section{Results}

Cybertutor, a virtual learning environment, is a rich resource that provides support to several education activities; in the present study, it was used for the insertion of information

Table 1 Questionnaire filled out by students after access to the cybertutor with contents on hearing health

\begin{tabular}{|l|l|l|l|l|l|}
\hline & Questions & Excellent & Satisfactory & Reasonable & Unsatisfactory \\
\hline 1 & Figure quality & & & & \\
\hline 2 & Video quality & & & & \\
\hline 3 & Animation quality & & & & \\
\hline 4 & Navigation ease & & & & \\
\hline 5 & Material disposition & & & & \\
\hline 6 & Content comprehension facility & & & & \\
\hline 7 & Vocabulary used & & & & \\
\hline 8 & Content organization & & & & \\
\hline 9 & $\begin{array}{l}\text { Presence of resources that clarify the } \\
\text { content (e.g., figures, pictures, videos, } \\
\text { animations, etc.) }\end{array}$ & & & & \\
\hline 10 & Content actualization & & & & \\
\hline 11 & Presence of links to other sites & & & & \\
\hline
\end{tabular}


Table 2 Topics contained in the two modules of cybertutor

\begin{tabular}{|c|c|c|}
\hline Topic & Module 1: hearing health & Module 2: intervention and rehabilitation \\
\hline $\mathrm{I}$ & Hearing & Treatment \\
\hline II & Nature of sound & $\mathrm{HA}$ \\
\hline III & How we hear sounds & $\mathrm{Cl}$ \\
\hline IV & Hearing skills & $\mathrm{HA}$ \\
\hline V & Hearing loss & An HA's functions \\
\hline VI & Causes of hearing loss & How an HA works \\
\hline VII & Hearing loss classification & Beneficiaries of HA use \\
\hline VIII & Hearing loss and language & How to use an $\mathrm{HA}$ \\
\hline IX & Prevention and treatment & How to care for an $\mathrm{HA}$ \\
\hline $\mathrm{x}$ & Otitis & \\
\hline $\mathrm{XI}$ & High-intensity sounds & \\
\hline XII & At school & \\
\hline XIII & Cleanliness and cares & \\
\hline XIV & Looking for help & \\
\hline
\end{tabular}

Abbreviations: $\mathrm{Cl}$, cochlear implant; $\mathrm{HA}$, hearing aid.

about hearing health, emphasizing basic concepts about the sounds, hearing, hearing abilities, hearing losses (causes and consequences), and possibilities of intervention and prevention of auditory alterations.
Thus, two modules about hearing health were obtained: "Hearing Health" with 14 topics and "Intervention and Rehabilitation" with nine topics. - Table 2 shows the themes of the topics.

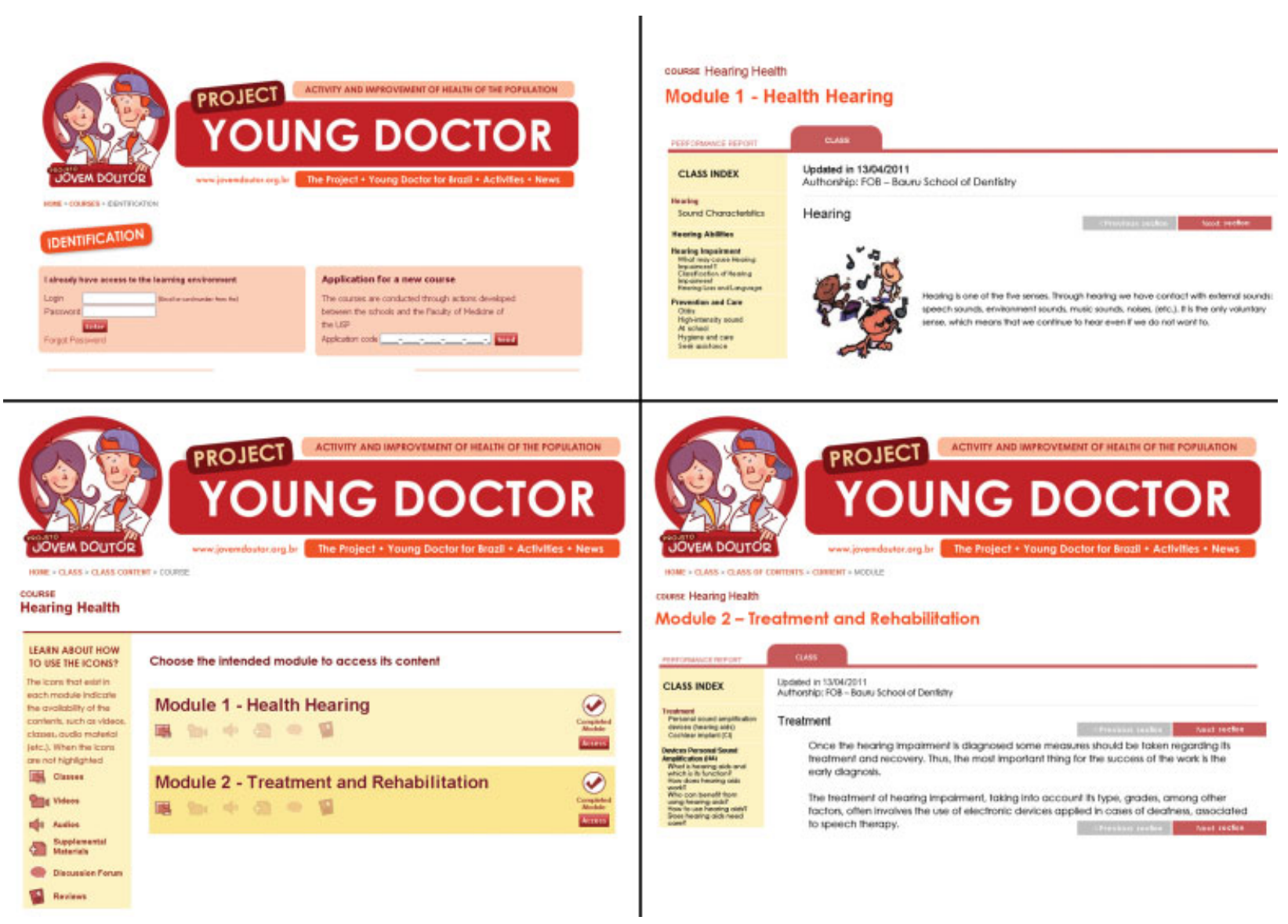

Fig. 2 Illustrative figure of the cybertutor tool and the inserted contents about hearing health. The website of the "Young Doctor Project" is in Portuguese (www.jovemdoutor.org.br) 
Thirty-seven static images were used in module 1, among figures and diagrams, and 5 videos; whereas for module 2 , there were 18 static images and 4 videos. Both modules were housed in the Young Doctor Project Web site (www.projetojovemdoutor.org.br), where a login and a password were needed to access the site (-Fig. 2 ).

After finishing the materials, the contents received scores in percentage of FERI. In - Fig. 3, the FERI percentage of the 14 topics of Module 1 can be observed. - Fig. 4 shows the FERI score obtained in Module 2 in the 9 topics constructed in cybertutor. Module 1 topics averaged 50.8\% in the FERI and the topics of Module 2, 51.4\%. These averages correspond to a reasonably difficult level in which users would need to have the attended middle school (fifth through eighth grades/sixth through ninth years) to guarantee the understanding of the language of the contents.

Subjectively, the 3 questions presented to the students referring directly to language were classified on average by $63 \%$ of students as excellent, by $30 \%$ as satisfactory, by $7 \%$ as reasonable, and by $0 \%$ as not satisfactory (-Fig. 5). The students using cybertutor rated the quality of the material as follows (-Fig. 6): $52.5 \%$ rated the quality as excellent, $41.3 \%$ as satisfactory, $6.2 \%$ as fair, and $0 \%$ as unsatisfactory. On average, $55.5 \%$ of participants considered the language and materials of contents in cybertutor excellent, $38.2 \%$ as satisfactory, $6.3 \%$ as reasonable, and $0 \%$ as not satisfactory.

\section{Discussion}

Based on this study, it was possible to declare that the adaptation of the language and use of illustrative resources allow students to access the scientific contents in a practical and satisfactory way. Health professionals, in particular the language and speech pathologists, must use resources of ICT to spread knowledge, allied to the leveling of the language, making the promotion of health possible, in this in case, that of the auditory health.

In all, 55 static images and 9 videos were used, keeping in mind the importance of illustrations for the achievement of knowledge and clarification of possible questions. In this way,

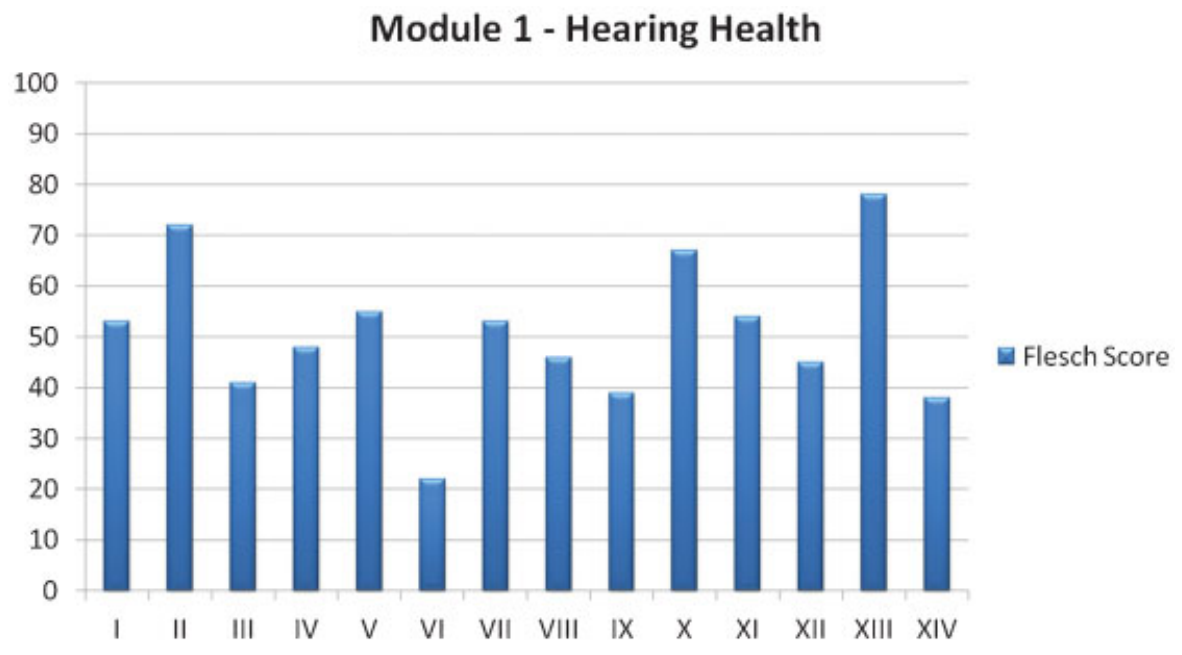

Fig. 3 Level of legibility of the topics of "Module 1-Hearing Health" inserted in the cybertutor, in percentage.

\section{Module 2 - Intervention and Rehabilitation}

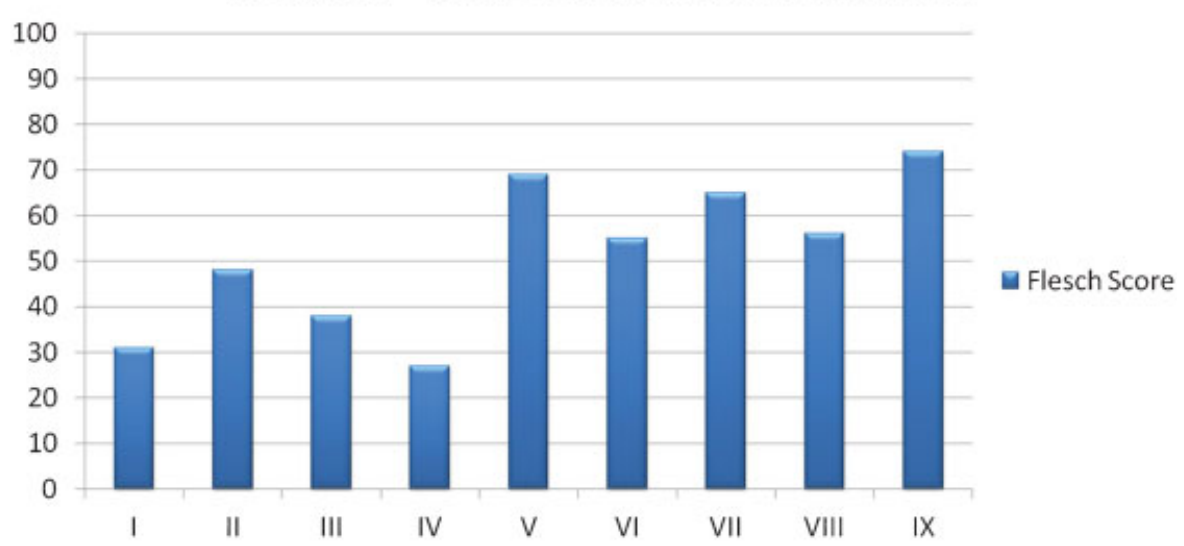

Fig. 4 Level of legibility of the topics of "Module 2-Intervention and Rehabilitation" inserted in cybertutor, in percentage. 


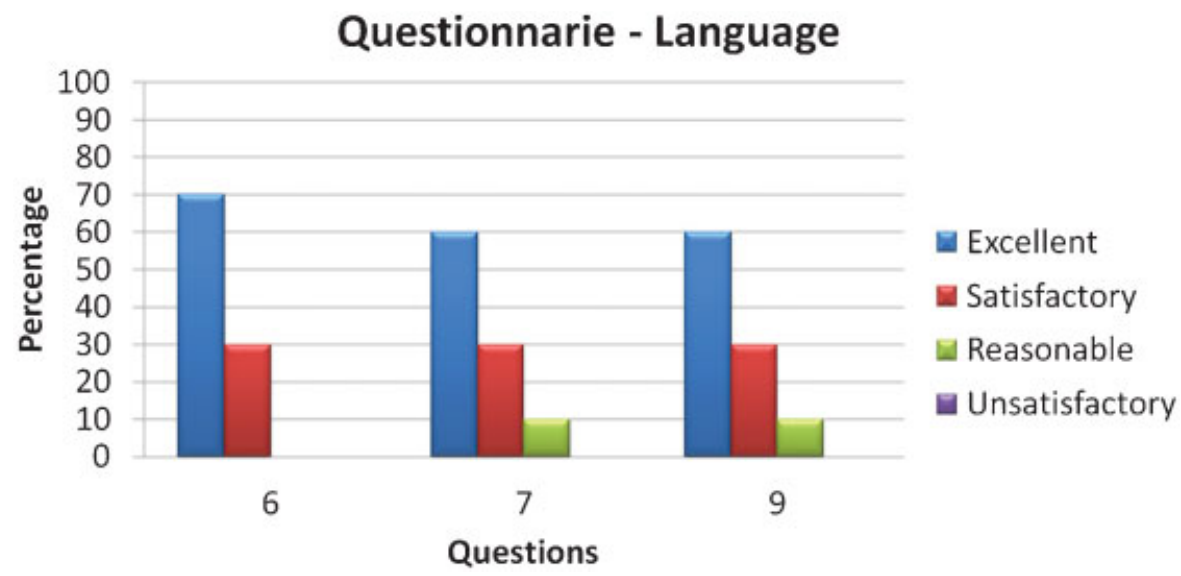

Fig. 5 Aspects about language, evaluated by the students, in percentage.

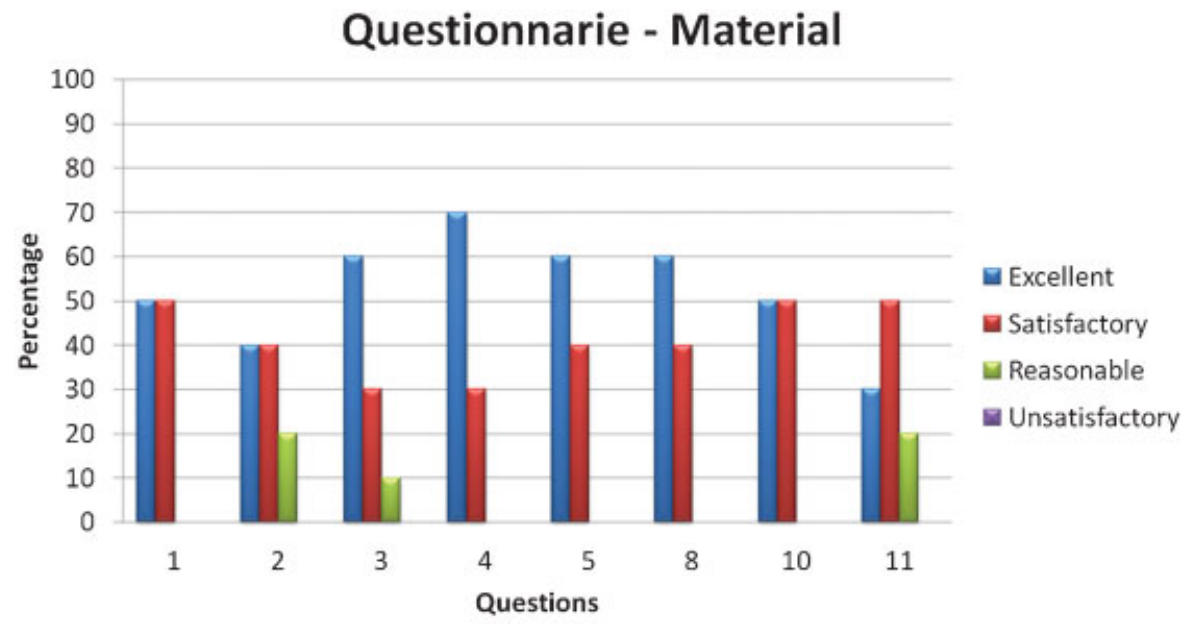

Fig. 6 Aspects on the material, evaluated by the students, in percentage.

topics with lower FERI were maintained because have a texts and other resources as figures and videos. When developing contents in ICT format, $92 \%$ of the medical students highlighted the importance of images for learning the available content. ${ }^{15}$

Specifically using cybertutors to transmit knowledge, two studies identified the importance of this tool to increase learning and better develop the abilities of the users on the subject in question. ${ }^{16,17}$ However, it must be highlighted that studies in this direction are few; only one research in audiology with the use of cybertutors for the education of speech and language pathology under graduate students was found. ${ }^{9}$

As to the use of other ICTs in the contribution of hearing health knowledge, scientific works demonstrated that this methodology is important in the learning process of undergraduate students of speech and language pathology, ${ }^{18}$ as well as in the orientation of patients with hearing deficiency who use personal sound amplification device ${ }^{19}$ and their relatives. ${ }^{20}$ The effectiveness of the learning through teleducation and its quality were similar to conventional methodologies of didactics. $^{21}$

The average score obtained on the FERI of this study corresponded to a reasonably difficult level, requiring a fifth- to eighth-grade (sixth- to ninth-year) education to understand it $^{8}$; the material was made available specifically for this age group, highlighting the importance of using simple language on the education material so that it has an ample scope, instructing the largest number of people. ${ }^{22}$

In the literature, only two studies in the field of audiology were found that used the Flesch Ease Reading test in their methodology. The first study's objective was to evaluate the ease of reading of the Hearing Handicap Inventory for Adults questionnaire. ${ }^{23}$ The second study evaluated the quality and legibility of the language of the information made available on hearing in 66 Web sites regarding hearing deficiency. The study demonstrated, based on the average score of the FERI, the need of the users to present the required minimum level of middle to high school or college education to be able to understand the information. ${ }^{24}$ No research using the FERI to evaluate the level of the legibility in cybertutors with contents of the area of the Audiology was found.

Complementing the FERI is the high satisfaction rate of the students due to the general quality of cybertutor; specifically, $93.7 \%$ of the students classified the language as excellent or satisfactory, bringing good acceptance of the developed 
material for dissemination of knowledge about hearing health. Other studies agree with this finding, demonstrating that students have considered several ICTs effective for the transmission of knowledge, because they make learning with interactive resources dynamic. ${ }^{25,26}$

It is highlighted that the objectives of the contents made available in CD-ROM, DVD, Web sites, and cybertutors can be different; however, in all the ICTs, the language level must be taken into consideration, in the attempt to guarantee the transmission of the displayed information; also, the opinion of the target population to which the content is directed should be considered, with the intention to provide the best interpretation and perception on several aspects such as language, illustrations, and organization, favoring the improvement and constant update of the tool.

\section{Conclusion}

Two modules on hearing health were created and inserted in a cybertutor, which received FERI indicating a facilitator level of language for the age group of the target population, and the students judged the quality of the material as excellent or satisfactory.

\section{Acknowledgments}

We thank Professor Chao Lung Wen, PhD, and the Telemedicine team of the Faculdade de Medicina da Universidade de São Paulo for making the cybertutor available on the Young Doctor Project's Web page and for the technical assistance in making this research possible.

Fonte de Auxílio

FAPESP-Fundação de Amparo à Pesquisa do Estado de São Paulo.

\section{Conflict of Interest}

None.

\section{References}

1 IBGE-Instituto Brasileiro de Geografia e Estatística. Censo Demográfico 2000. Rio de Janeiro, Brasil: IBGE; 2010 [Accessed May 13, 2013]. Available at: http://www.censo2010.ibge.gov.br

2 Brasil. Ministério da Saúde. Secretaria de Atenção à Saúde. Política Nacional de Saúde da Pessoa Portadora de Deficiência. Brasília, Brasil: Editora do Ministério da Saúde; 2008

3 Pupo AC, Balieiro CR, Figueiredo RSL. Estudo retrospectivo de crianças e jovens com deficiência auditiva: caracterização das etiologias e quadro audiológico. Rev CEFAC. 2008;10(1):84-91

4 Kochkin S. MarkeTrak VII: obstacles to adult non-user adoption of hearing aids. Hear J. 2007;60(4):27-43

5 Maia RM, Silva MAM, Tavares PMB. Saúde auditiva dos recémnascidos: atuação da fonoaudiologia na Estratégia Saúde da Família. Rev CEFAC 2012;14(2):206-214

6 Ornes CR, Miguel V, Fernández M, Páez J. Capacitación a distancia en lactancia materna. Rev Fac Med (Caracas) 2002;25(1):100-103
7 Soirefmann M, Boza JC, Comparin C, Cestari TF, Wen CL. Cybertutor: a teaching tool in dermatology. An Bras Dermatol 2010;85(3): 400-402

8 Biondo-Simões MLP, Martynetz J, Ueda FMK, Olandoski M. Compreensão do Termo de Consentimento. Rev Col Bras Cir 2007; 43(3):183-188

9 Blasca WQ Maximino LP, Godoy D, Picolini MM, Campos K. Novas tecnologias educacionais no ensino da audiologia. Rev CEFAC 2010;2:20-25

10 Cruz OLM, Zanoni A. Projeto Homem Virtual-Audição v.1 [CDROM]. São Paulo, Brasil: Disciplina de Telemedicina da Faculdade de Medicina da Universidade de São Paulo; 2009

11 Blasca WQ Ferrari DV. Projeto Homem Virtual-Aparelho de Amplificação Sonora Individual [CD-ROM]. São Paulo, Brasil: Disciplina de Telemedicina da Faculdade de Medicina da Universidade de São Paulo; 2008

12 Blasca WQ Vianna LS, Campos K, Ascencio ACS, Oliveira JRM, Moretti ALM. A construção de um DVD motivacional sobre a comunicação com o aparelho de amplificação sonora individual. In: Anais do $26^{\circ}$ Encontro Internacional de Audiologia; 2011; Alagoas. Maceió, Brasil: Academia Brasileira de Audiologia; 2011:2964

13 Blasca WQ Campos K. Conhecendo e aprendendo sobre o meu aparelho auditivo [DVD]. Bauru, Brasil: TBR Produções; 2010

14 Barbosa AL, Martins EN. Evaluation of Internet websites about floaters and light flashes in patient education. Arq Bras Oftalmol 2007;70(5):839-843

15 Roubidoux MA, Chapman CM, Piontek ME. Development and evaluation of an interactive Web-based breast imaging game for medical students. Acad Radiol. 2002;9(10):1169-1178

16 de Sousa Eskenazi E, de Arruda Martins M, Ferreira M Jr. Oral health promotion through an online training program for medical students. J Dent Educ 2011;75(5):672-678

17 Marques CMS, Egry EY, Silva MB, et al. Tele-education and competencies assessment to Brazilian's auxiliary nurse. Rev Esc Enferm USP 2007;41(Spec No):841-846

18 Blasca WQ Mantovani DA, Campos PD, Ascencio ACS, Campos K, Alvarenga KF. A new proposal for teaching psychoacoustics. Rev CEFAC. 2012. Accessed on May 13, 2013. Available at: http://www. scielo.br/pdf/rcefac/2012nahead/en_143-11.pdf

19 Campos K, Oliveira JRM, Blasca WQ. Processo de adaptação de aparelho de amplificação sonora individual: elaboração de um DVD para auxiliar a orientação a indivíduos idosos. Rev Soc Bras Fonoaudiol. 2010;15(1):19-25

20 Ferrari DV. Therapeutic patient education via tele-audiology: Brazilian experiences. Hear Rev. 2012;19(10):40-43

21 Haney M, Silvestri S, Van Dillen C, Ralls G, Cohen E, Papa L. A comparison of tele-education versus conventional lectures in wound care knowledge and skill acquisition. J Telemed Telecare 2012;18(2):79-81

22 Correa CC, Ferrari DV. Berretin-Felix. Quality, range and legibility in websites related to orofacial functions. Arq Int Otorrinolaringol. 2013. Forthcoming

23 Aiello CP, Lima II, Ferrari DV. Validity and reliability of the hearing handicap inventory for adults. Braz J Otorhinolaryngol 2011; 77(4):432-438

24 Laplante-Lévesque A, Brännström KJ, Andersson G, Lunner T. Quality and readability of English-language internet information for adults with hearing impairment and their significant others. Int J Audiol 2012;51(8):618-626

25 Vieira MMRM, Berretin-Felix G, Brasolotto AG. The Virtual Man Project's CD-ROM “Voice Assessment: Speech-Language Pathology and Audiology \& Medicine," Vol. 1. J Appl Oral Sci 2009;17 (Suppl):43-49

26 Wu WH, Chen WF, Fang LC, Lu CW. Development and evaluation of web service-based interactive and simulated learning environment for computer numerical control. Comput Appl Eng Educ 2010;18(3):407-422 